\title{
CORRECTION
}

K. Zhukovsky · D. Oskolkov

\section{Correction to: Exact harmonic solutions to Guyer-Krumhansl-type equation and application to heat transport in thin films}

Published online: 5 April 2018

(C) Springer-Verlag GmbH Germany, part of Springer Nature 2018

Correction to: Continuum Mech. Thermodyn.

https://doi.org/10.1007/s00161-018-0648-4

Unfortunately, Eq. (14) was incorrectly published in the original publication and the correct equation is provided here.

$$
C_{1}=-\mathrm{e}^{\frac{T}{2} \varepsilon_{\mathrm{eff}}} \frac{B \mathrm{e}^{-\frac{T}{2}\left(\varepsilon_{\mathrm{eff}}-\sqrt{U}\right)}-G}{\mathrm{e}^{-\frac{T}{2} \sqrt{U}}-\mathrm{e}^{\frac{T}{2} \sqrt{U}}}, \quad C_{2}=B-C_{1} .
$$

The original article can be found online at https://doi.org/10.1007/s00161-018-0648-4.

K. Zhukovsky $(\varangle) \cdot$ D. Oskolkov

Faculty of Physics, M.V. Lomonosov Moscow State University, Leninskie Gory, Moscow, Russia 119991

E-mail: zhukovsk@physics.msu.ru 